\title{
The role of transcatheter approaches for the treatment of pulmonary homograft dysfunction
}

\author{
Bahaa M. Fadel ${ }^{1,2}$, Dania Mohty ${ }^{1,2,3}$, Khadija Alassas ${ }^{4}$, Zohair Alhalees ${ }^{1,2}$ \\ ${ }^{1}$ King Faisal Specialist Hospital \& Research Center, Riyadh, Saudi Arabia; ${ }^{2}$ Alfaisal University, Riyadh, Saudi Arabia; ${ }^{3} \mathrm{CHU}$ Limoges, Limoges, \\ France; ${ }^{4}$ Salmaniya Medical Complex, Manama, Bahrain \\ Correspondence to: Bahaa M. Fadel. King Faisal Specialist Hospital \& Research Center, Heart Center, PO Box 3354, MBC \# 16, Riyadh, 11211, Saudi \\ Arabia. Email: fadelbahaa@gmail.com.
}

Submitted Aug 13, 2020. Accepted for publication Dec 23, 2020.

doi: 10.21037 /acs-2020-rp-12

View this article at: http://dx.doi.org/10.21037/acs-2020-rp-12

More than fifty years after its inception, the Ross procedure continues to have indications due to its numerous advantages and obvious limitations of alternative replacement options for the aortic valve; particularly in the young patient population, including infants and neonates. Traditionally, the pulmonary valve (PV), used as an autograft, is replaced with a pulmonary homograft or, less often, another valve substitute. The Achilles' heel of the Ross procedure is the potential for future prosthetic disease of the right ventricular outflow tract (RVOT) (1).

Replacement of the pulmonary autograft with a homograft or another substitute poses diagnostic and therapeutic challenges to Clinicians managing Ross patients. Homograft dysfunction, while not uncommon, is usually well tolerated for many years, particularly as Ross patients most often have normal pulmonary vascular resistance. In patients with severe homograft dysfunction, the development of symptoms or the progressive dilatation and/or failure of the right ventricle are accepted indications for reintervention, with rates widely varying from $4 \%$ to $16 \%$ at ten-year follow-up $(1,2)$. Reinterventions have traditionally consisted of a redo surgical pulmonary valve replacement (SPVR) using a new homograft.

Advances in delivery systems and innovations in valve design over the past twenty years have allowed for the emergence of transcatheter pulmonary valve replacement (TPVR) as an attractive alternative to SPVR. Three such transcatheter balloon expandable valves are currently in use in the pulmonary position. These include the Melody ${ }^{\circledR}$ TPV (Medtronic, Inc., Minneapolis, MN, USA), the Edwards SAPIEN XT THV, and the SAPIEN 3 THV
(Edwards Lifesciences, Irvine, CA, USA). Several others are currently under development or in clinical trials (3). The prospect for TPVR is to avoid cardiopulmonary bypass and provide a less invasive intervention than SPVR with the hope of decreasing morbidity, shortening hospital stay, reducing expenditure and lowering mortality. All this makes the percutaneous approach a logical ideal and futuristic mode of therapy. The circular shape of the right ventricular outflow in Ross patients is felt to facilitate deployment of the transcatheter valve by providing a favorable anatomic substrate, thus improving procedural success (4). The question remains whether, thus far, TPVR has lived to fulfill its expectations?

Limited outcome data is available in the Ross population to examine the value of TPVR versus SPVR or, to establish the superiority of one type of intervention over another. One study from our institution retrospectively compared the outcome of Ross patients who underwent TPVR, mostly using a Melody valve, or SPVR, using a homograft (1). Both types of intervention carried no procedure-related mortality, a low rate of peri-procedural complications and comparable midterm outcomes. Whereas a greater progression to homograft dysfunction was noted with SPVR, this did not translate into a higher rate of repeat PV interventions. An interesting finding was a higher rate of PV infective endocarditis in the TPVR group (1).

An important result in our study was the high percentage of SPVR patients who underwent concomitant intervention(s) at the time of surgery, mostly for associated valve disease. The choice of intervention, whether transcatheter or surgical, was clearly influenced by the need 
for additional surgical procedure(s). Even though both approaches led to a similar outcome, the fact that TPVR proved to be non-inferior to the gold standard SPVR is an important finding (1).

Emerging data indicates some of the complications encountered with TPVR are associated with the use of the Melody ${ }^{\circledR}$ valve, the first marketed and most commonly used transcatheter valve in the pulmonary position. The Melody valve carries a higher rate of stent fracture than the SAPIEN XT THV with potential obstruction to flow and need for reintervention (5). Additionally, a higher rate of infective endocarditis is noted with the Melody valve (6), similar to its predecessor; the surgically implanted Contegra bovine jugular vein valved conduit (7). Notably, these complications do not negatively impact event-free survival or freedom from reinterventions as compared to SPVR in a non-Ross population (8). The association between the prosthesis brand and specific complications gives hope that future generations of transcatheter valves with improved design might lead to a lower complication rate.

No data currently indicates that Ross patients fare differently in the long-term than non-Ross patients with PV homograft who undergo TPVR. One exception worth mentioning is that Ross patients exhibit a higher risk of intraprocedural coronary artery compression by the valve stent, a complication that would prompt conversion to SPVR (9).

TPVR has turned into a mainstream mode of therapy to make uncertain the future place of routine SPVR (10). It may become increasingly difficult for caretakers to justify recommending redo SPVR to many patients who can otherwise be treated percutaneously and therefore, patient selection is crucial. Good indications for either SPVR or a hybrid procedure include the requirement for concomitant cardiac intervention, a small body size in whom negotiating the right heart with large delivery systems may lead to hemodynamic instability, a significantly enlarged RVOT and patients at risk of TPVR related complications, such as coronary compression or worsening of aortic regurgitation.

The field of percutaneous valve technology is rapidly evolving, far outpacing the progress in operative techniques or the design of surgical prostheses. Advances in transcatheter aortic valve design and delivery systems are benefitting the field of transcatheter PVs. With newer transcatheter valves on the horizon, the indications for TPVR versus SPVR will continue to be refined. Timing of reintervention on the PV would also be revisited if newer transcatheter devices carry such a low morbidity and complication rate to justify an even earlier intervention on the PV, prior to development of subtle right ventricular dysfunction. There is certainly a need for prospective randomized controlled trials to better determine the indications and choice of percutaneous versus surgical approach with the necessity for long term follow-up.

The future will certainly be driven by innovations in technology aimed at reducing mortality and alleviating morbidity. The ultimate valve would be durable, carry minimal prosthesis-related complications, easily implantable in the least invasive manner and at the lowest risk to the patient. Indicators suggest that we are already on our way, but there is still progress to be made.

\section{Acknowledgments}

Funding: None.

\section{Footnote}

Conflicts of Interest: The authors have no conflicts of interest to declare.

Open Access Statement: This is an Open Access article distributed in accordance with the Creative Commons Attribution-NonCommercial-NoDerivs 4.0 International License (CC BY-NC-ND 4.0), which permits the noncommercial replication and distribution of the article with the strict proviso that no changes or edits are made and the original work is properly cited (including links to both the formal publication through the relevant DOI and the license). See: https://creativecommons.org/licenses/by-nc-nd/4.0/.

\section{References}

1. Alassas K, Mohty D, Clavel MA, et al. Transcatheter versus surgical valve replacement for a failed pulmonary homograft in the Ross population. J Thorac Cardiovasc Surg 2018;155:1434-44.

2. Sievers HH, Stierle U, Petersen M, et al. Valve performance classification in 630 subcoronary Ross patients over 22 years. J Thorac Cardiovasc Surg 2018;156:79-86.e2.

3. Giugno L, Faccini A, Carminati M. Percutaneous Pulmonary Valve Implantation. Korean Circ J 2020;50:302-16.

4. Nordmeyer J, Lurz P, Tsang VT, et al. Effective transcatheter valve implantation after pulmonary 
homograft failure: a new perspective on the Ross operation. J Thorac Cardiovasc Surg 2009;138:84-8.

5. Nordmeyer J, Khambadkone S, Coats L, et al. Risk stratification, systematic classification, and anticipatory management strategies for stent fracture after percutaneous pulmonary valve implantation. Circulation 2007;115:1392-7.

6. Lehner A, Haas NA, Dietl M, et al. The risk of infective endocarditis following interventional pulmonary valve implantation: A meta-analysis. J Cardiol 2019;74:197-205.

7. Beckerman Z, De León LE, Zea-Vera R, et al. High incidence of late infective endocarditis in bovine jugular vein valved conduits. J Thorac Cardiovasc Surg

Cite this article as: Fadel BM, Mohty D, Alassas K, Alhalees $\mathrm{Z}$. The role of transcatheter approaches for the treatment of pulmonary homograft dysfunction. Ann Cardiothorac Surg 2021;10(4):521-523. doi: 10.21037/acs-2020-rp-12
2018;156:728-34.

8. Georgiev S, Ewert P, Eicken A, et al. Munich Comparative Study: Prospective Long-Term Outcome of the Transcatheter Melody Valve Versus Surgical Pulmonary Bioprosthesis With Up to 12 Years of Follow-Up. Circ Cardiovasc Interv 2020;13:e008963.

9. Gillespie MJ, McElhinney DB, Kreutzer J, et al. Transcatheter Pulmonary Valve Replacement for Right Ventricular Outflow Tract Conduit Dysfunction After the Ross Procedure. Ann Thorac Surg 2015;100:996-1002; discussion 1002-3.

10. Morgan GJ. Pulmonary Regurgitation- Is the Future Percutaneous or Surgical? Front Pediatr 2018;6:184. 